\title{
Influence of complex chemical additives on the rheological properties of cement paste and concrete mixture
}

\author{
Urinbek Turgunbaev $^{1^{*}}$, and Bobur Toxirov ${ }^{1}$ \\ ${ }^{1}$ Tashkent State Transport University, Tashkent, Uzbekistan
}

\begin{abstract}
The article studies the effect of complex chemical additives on the water demand of cement, the setting time of the cement paste, the consumption of cement and additives KJ-3 on the viscosity of the concrete mixture, and also determines the normal density of the cement paste without the additive and with the plasticizing additive and the rheological characteristics of the concrete mixture with the additive KJ- 3 .
\end{abstract}

\section{Introduction}

The purpose is to reduce the use of superplasticizers in cement needs water systems and improve the strength of concrete mixtures.

We have carried out a set of theoretical and practical research to study the effect of chemical additives in the water demand of the Portland cement and concrete made on its basis and the kinetics of hardening [7-15].

At the same time, the effect of complex chemical additives of KJ-3 and KJ-3MB grades on the kinetics of hardening and water demand of Portland cement produced by JSC "Akhangarancement" was studied.

\section{Materials and Methods}

The rheological properties of the cement paste were determined following the requirements of GOST 310.3-76, using a Vika device [2-6].

The effect of complex chemical additives on reducing the water demand of cement $\left(\mathrm{C}_{\mathrm{W}}\right)$ was calculated using the following formula:

$$
C_{w}=\left[\left(N_{d}-N_{d p}\right) / N_{d}\right] \cdot 100 \%
$$

Where $\mathrm{N}_{\mathrm{d}}$ and $\mathrm{N}_{\mathrm{dp}}$ are the normal density of the cement paste without additive and with a plasticizing additive. The research results are shown in table.1.

With the introduction of the additive $\mathrm{KJ}-3 \mathrm{MB}$ in an amount of up to $5 \%$, the normal density of the cement paste did not change. Therefore, the water demand of cement was studied with the addition of $10 \% \mathrm{KJ}-3 \mathrm{MB}$.

\footnotetext{
*Corresponding author: urinbekdj@mail.ru
} 
As seen from the results presented in Table 1, the two chemical additives may reduce the water demand of the cement paste $[5,11,17,20]$. In this case, the influence exerted by the addition of KJ-3 is slightly higher about KJ-3MB. Simultaneously, an increase in the share of chemical additives $\mathrm{KJ}-3$ by more than $1 \%$ is economically inexpedient and ineffective since it can lead to an increase in the cost of construction $[8,9,11,16,18]$.

Table 1. The effect of complex chemical additives on the water demand of cement

\begin{tabular}{|c|c|c|c|c|c|c|}
\hline \multirow{2}{*}{$\begin{array}{c}\text { Additive } \\
\text { brand }\end{array}$} & \multicolumn{6}{|c|}{ Reducing the water demand of the cement paste, \% } \\
\cline { 2 - 7 } & \multicolumn{6}{|c|}{ The amount of additive, in\% of the mass of cement } \\
\cline { 2 - 7 } & 0.2 & 0.3 & 0.6 & 0.9 & 1.2 & 1.5 \\
\hline KJ-3 & 8.0 & 17.5 & 23.0 & 25.5 & 29.0 & 30.0 \\
\hline & \multicolumn{7}{|c|}{ The amount of additive, in \% of the mass of cement } \\
\hline \multirow{3}{*}{ KJ-3MB } & 1 & 3 & 6 & 9 & 12 & 15 \\
\cline { 2 - 7 } & 5.0 & 11.3 & 20.2 & 24.0 & 25.5 & 27.5 \\
\hline
\end{tabular}

The effect of these additives on the setting time of the cement paste was studied in accordance with the requirements of GOST 3103-76. The results are shown in Table 2 and Figure 1.

Table 2. Influence of complex chemical additives on the setting time of cement paste

\begin{tabular}{|c|c|c|c|c|c|c|c|}
\hline \multirow{2}{*}{$\begin{array}{c}\text { Additive } \\
\text { brand }\end{array}$} & \multirow[t]{2}{*}{ Setting time of cement paste } & \multicolumn{6}{|c|}{ The amount of additive, in $\%$ of the mass of cement } \\
\hline & & 0.0 & 0.3 & 0.6 & 0.9 & 1.2 & 1.5 \\
\hline \multirow[t]{2}{*}{ KJ-3 } & Setting start (hour, min.) & 2.10 & 3.20 & 3.20 & 4.00 & 4.15 & 4.20 \\
\hline & End of setting (hour, min.) & 4.05 & 4.10 & 4.25 & 5.00 & 5.20 & 5.30 \\
\hline \multirow{4}{*}{$\begin{array}{c}\mathrm{KJ}-3 \\
\mathrm{MB}\end{array}$} & & \multicolumn{6}{|c|}{ The amount of additive, in $\%$ of the mass of cement } \\
\hline & & 0.0 & 3 & 6 & 9 & 12 & 15 \\
\hline & Setting start (hour, min.) & 2.10 & 3.00 & 3.10 & 3.40 & 4.00 & 4.10 \\
\hline & End of setting (hour, min.) & 4.05 & 4.10 & 4.15 & 4.45 & 5.00 & 5.10 \\
\hline
\end{tabular}

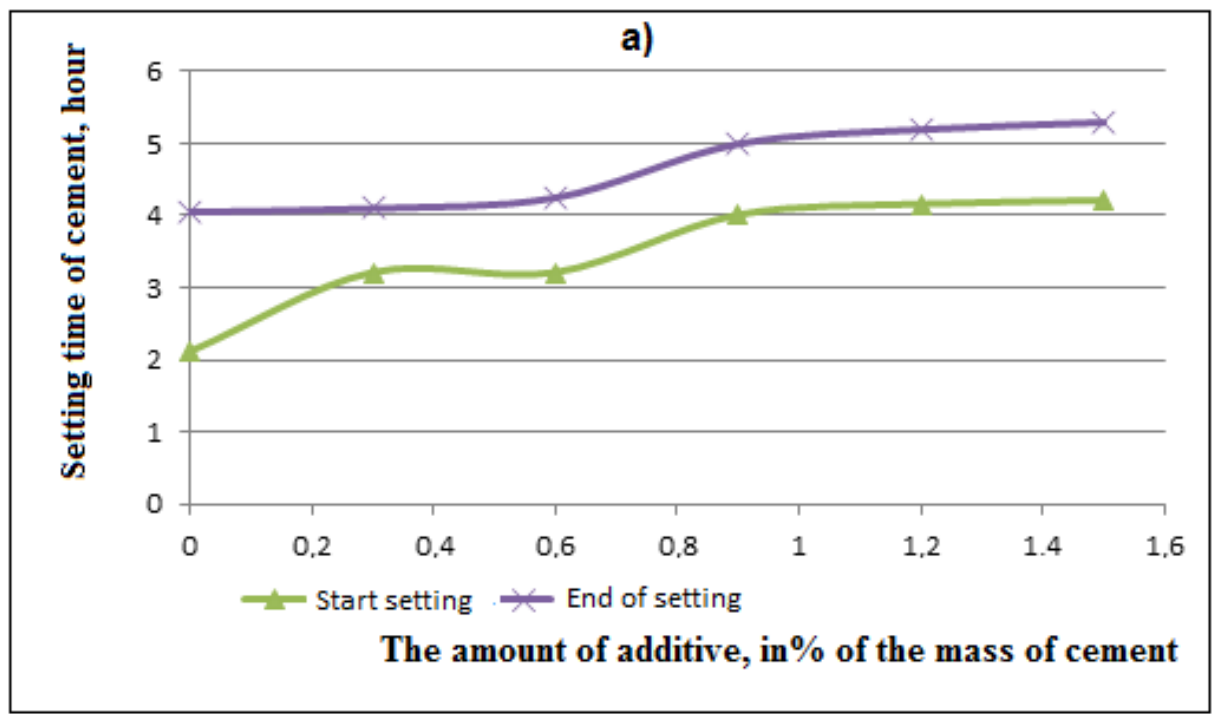




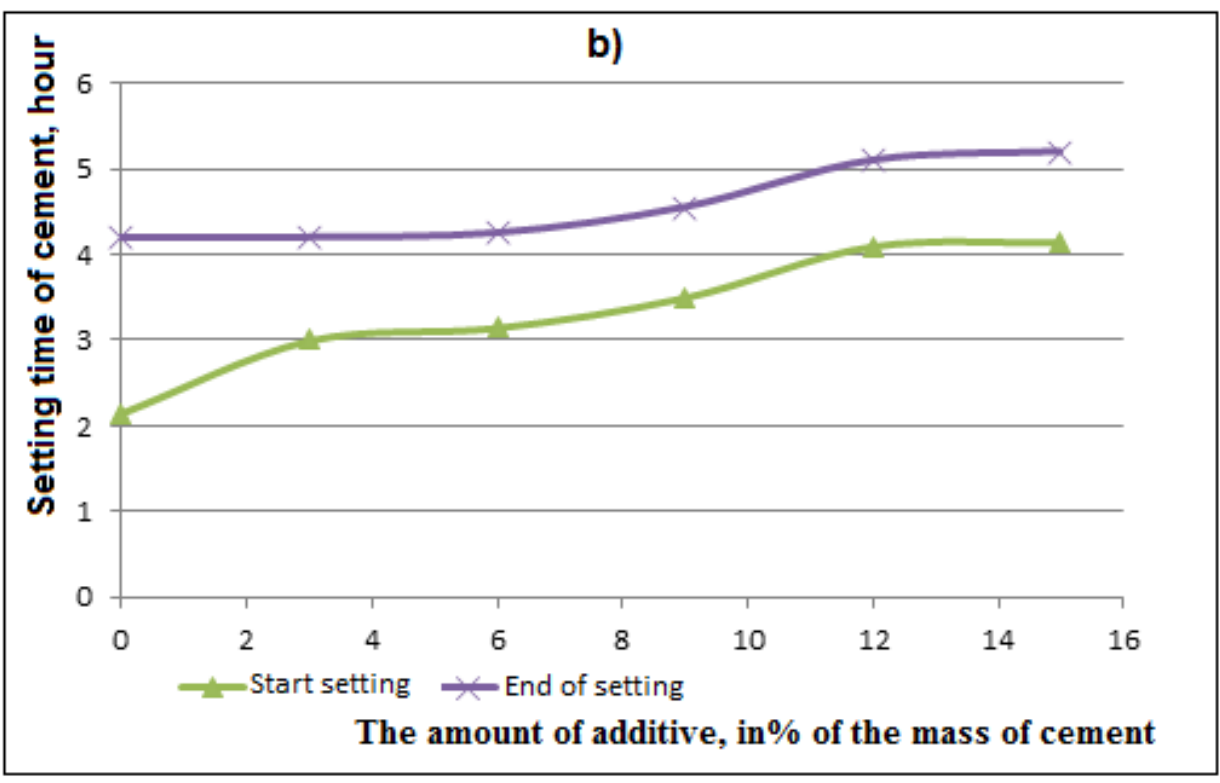

Fig. 1. Effect of chemical additives KJ-3 (a) and KJ-3 MB (b) on the setting time of the cement paste

\section{Results and Discussion}

The experimental studies have shown that complex chemical additives contribute to a certain reduction in the time for the onset of the setting of the cement paste.

The construction of railway tracks, reinforced concrete sleepers are used, manufactured on specialized lines of reinforced concrete factories. Production of sleepers Ш1 and Ш2 following GOST 10629-88 are made of heavy concrete of strength class B40.

For the construction and reconstruction of railway platforms, the following reinforced concrete products are required: reinforced concrete racks (R), reinforced concrete piles (CP), reinforced concrete foundations of the glass type (FG), reinforced concrete foundation blocks (CFB), reinforced concrete beams (B or CB), reinforced concrete ribbed slabs (S, 2S1), reinforced concrete flights of stairs (FS) or stair steps (SS). For their manufacture, concretes on PC M 400 of classes B22.5, B30 and B40 are widely used [1]. Therefore, from the initial materials accepted for research, we first determined the control compositions of these concretes. The calculations were performed on a personal computer using the EXEL program. The concrete compositions obtained by the calculationexperimental method are given in table 3 .

Table 3. Control compositions of concrete at PC M 400 D20

\begin{tabular}{|c|c|c|c|c|c|c|c|}
\hline Concrete & \multirow{2}{*}{$\begin{array}{c}\text { O.K., } \\
\text { class }\end{array}$} & \multicolumn{6}{|c|}{ Material consumption per $1 \mathrm{~m}^{3}(\mathrm{~kg})$} \\
\cline { 3 - 8 } & $\mathrm{cm}$ & $\mathrm{C}$ & $\mathrm{S}$ & $\mathrm{R}$ & $\mathrm{W}$ & $\mathrm{W} / \mathrm{C}$ & $\mathrm{S} / \mathrm{R}$ \\
\hline B 22.5 & $4-6$ & 370 & 620 & 1200 & 204 & 0.55 & 0.52 \\
\hline B 30 & $4-6$ & 450 & 645 & 1175 & 225 & 0.5 & 0.55 \\
\hline B 40 & $4-6$ & 492 & 650 & 1155 & 235 & 0.47 & 0.56 \\
\hline
\end{tabular}

Then, by the same method, the compositions of the concrete mixture with the addition of KJ-3 -1\% were determined. The obtained concrete compositions on PC M 400 D0 and D 20 are given in tables 3 and 4. 
Table 4. Control compositions of concrete at PC M 400 D20

\begin{tabular}{|c|c|c|c|c|c|c|c|c|}
\hline Concrete & O.K., & \multicolumn{7}{|c|}{ Material consumption per $1 \mathrm{~m}^{3}(\mathrm{~kg})$} \\
\cline { 3 - 9 } class & $\mathrm{cm}$ & $\mathrm{C}$ & $\mathrm{S}$ & $\mathrm{R}$ & $\mathrm{W}$ & $\mathrm{W} / \mathrm{C}$ & $\mathrm{D}, \%$ & $\mathrm{~S} / \mathrm{R}$ \\
\hline B 27.5 & $12-16$ & 292 & 780 & 1170 & 130 & 0.445 & 1.0 & 0.67 \\
\hline B 30 & $12-16$ & 320 & 765 & 1140 & 130 & 0.351 & 1.0 & 0.67 \\
\hline B 40 & $12-16$ & 370 & 750 & 1125 & 130 & 0.356 & 1.0 & 0.67 \\
\hline
\end{tabular}

Data analysis table 4 shows that due to the plasticizing effect of the action at the consumption of cement for the control compositions with the dosage of the KJ-3 additive $1 \%$, it is possible to obtain concrete mixtures with an OD of $12-16 \mathrm{~cm}$ and compressive strength of 36,42 and $56 \mathrm{MPa}$, corresponding to the classes of concrete $\mathrm{B} 27.5$; B30, and B40.

It is known that the main rheological properties of a concrete mixture depend on three parameters: adhesion, internal friction and a viscosity [2].

To ensure the fluidity of the mixture, it is necessary to overcome the shear threshold caused by the forces of adhesion and internal friction. The lower its viscosity, the higher the mobility of the mixture. These three factors are independent of each other, and workability is determined by their interaction.

The relative mobility of the concrete mix for decades usually determined experimentally by a slump. The method is simple and convenient. However, the cone method does not directly correlate the amount of cone settlement and the formability of the concrete mixture. It is not always possible to correctly assess the formability and compaction of the concrete mixture by the value of the cone slump since the thixotropic transformations are not taken into account when determining these properties [3].

The study of the viscosity of a concrete mixture is based on the use of hydrodynamic methods for high-viscosity fluids. This allows you to get calculated dependencies for their determination. The concrete mixture is considered as an incompressible fluid of high viscosity. The process of the concrete mixture flowing out of the hole is described by the equation from classical hydrodynamics $[4,19]$ :

$$
\eta=\frac{d \cdot \omega \cdot g}{24 \cdot S \cdot \ln \left|H-\frac{\rho}{\rho}\right|_{H_{2}}^{H_{3}} x \rho \cdot T}
$$

where: $\eta$ is viscosity, $P_{a x c}$; T is expiration time of the concrete mix, sec; $\rho$ is the density of the concrete mixture, $\mathrm{g} / \mathrm{cm}^{3} ; \mathrm{d}$ is reduced hole diameter, $\mathrm{m} ; \omega$ is outlet area, $\mathrm{m}^{2} ; \mathrm{g}$ is acceleration of gravity $\left(10 \mathrm{~m} / \mathrm{s}^{2}\right) ; \mathrm{S}$ is cross-sectional area of the device, $\mathrm{m}^{2} ; \mathrm{H}$ is mixture level height in the device, $\mathrm{m}$; $\mathrm{P}$ is specific pressure on a free surface, $\mathrm{N} / \mathrm{m}^{2}$.

If we consider that the size of the device and the test conditions are constant, formula 1 takes the following form:

$$
\eta=12.5 \cdot \rho \cdot T
$$

Investigations into the influence of $\mathrm{KJ}-3$ additives on the viscosity of the concrete mixture were carried out on the concrete compositions given in Table 3-4. The dosage of additives is taken equal to $0.3 ; 0.6 ; 1$ and $1.2 \%$ by weight of the binder. 


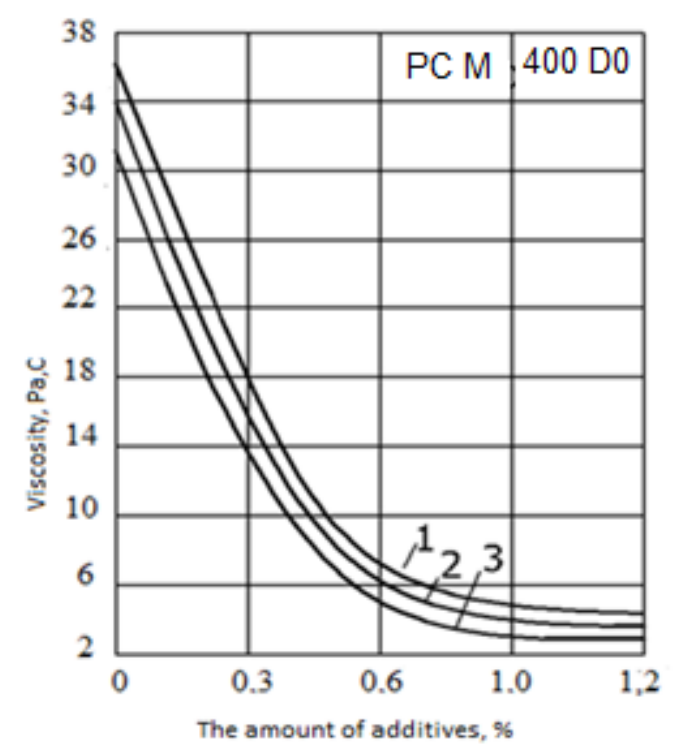

Fig. 2. Influence of the consumption of cement and KJ-3 additives on the viscosity of the concrete mixture: 1, 2, 3 are concrete mix with cement consumption 292,320 and $370 \mathrm{~kg} / \mathrm{m}^{3}$, respectively

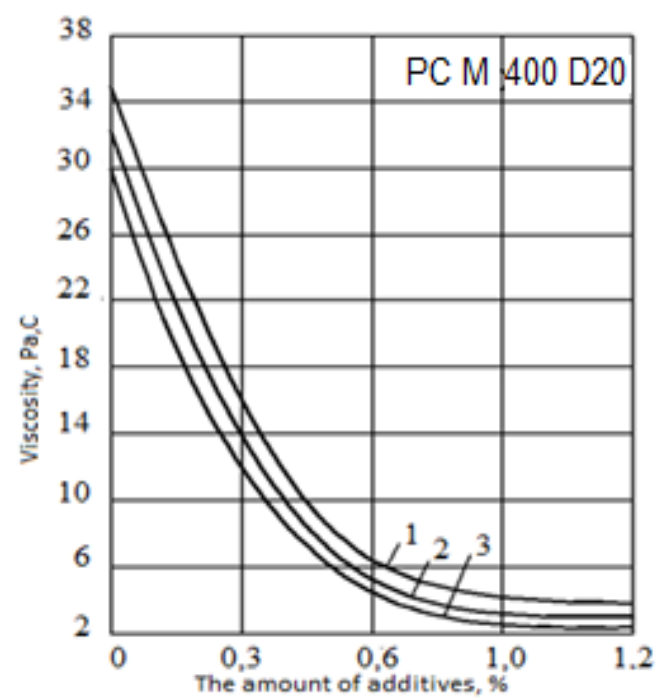

Fig. 3 Influence of the consumption of cement and additives KJ-3 on the viscosity of the concrete mixture

The results of experimental studies are shown in Figures 2-3 and table 5. 
Table 5. Rheological characteristics of concrete mix with KJ-3 additive

\begin{tabular}{|c|c|c|c|c|c|c|c|}
\hline № & $\begin{array}{c}\text { Dosage of } \\
\text { superplastic, } \\
\%\end{array}$ & $\begin{array}{c}\text { Cone } \\
\text { draft, } \\
\mathrm{mm}\end{array}$ & $\begin{array}{l}\text { Expiration } \\
\text { time T, } \\
\text { min }\end{array}$ & $\begin{array}{c}\text { The } \\
\text { density of } \\
\text { the } \\
\text { concrete } \\
\text { mix } \rho, \mathrm{g} / \\
\mathrm{cm}^{3}\end{array}$ & $\begin{array}{l}\text { Experimental } \\
\text { viscosity, } \\
\eta \times 10-3 \text {, Paxc }\end{array}$ & $\begin{array}{c}\text { Einstein's } \\
\text { formula } \\
\text { viscosity, } \\
\eta_{\mathrm{mx}} 10^{-3}\end{array}$ & $\begin{array}{l}\text { Mobility } \\
1 / \eta 10^{-3}\end{array}$ \\
\hline \multicolumn{8}{|c|}{ S / C M400 D 20 cement consumption $292 \mathrm{~kg} / \mathrm{m}^{3}$} \\
\hline 1 & 0 & 40 & 98 & 2.28 & 2.8 & 2.79 & 0.35 \\
\hline 2 & 0.3 & 80 & 49 & 2.31 & 1.4 & 1.41 & 0.68 \\
\hline 3 & 0.6 & 120 & 25 & 2.31 & 0.7 & 0.72 & 1.36 \\
\hline 4 & 1 & 140 & 18 & 2.33 & 0.5 & 0.52 & 1.89 \\
\hline 5 & 1.2 & 160 & 14 & 2.34 & 0.43 & 0.41 & 2.40 \\
\hline \multicolumn{8}{|c|}{ S/C M400 D 20 cement consumption $320 \mathrm{~kg} / \mathrm{m}^{3}$} \\
\hline 1 & 0 & 50 & 90 & 2.29 & 2.52 & 2.57 & 0.37 \\
\hline 2 & 0.3 & 90 & 43 & 2.31 & 1.2 & 1.24 & 0.80 \\
\hline 3 & 0.6 & 130 & 20 & 2.32 & 0.56 & 0.58 & 1.76 \\
\hline 4 & 1 & 150 & 16 & 2.34 & 0.46 & 0.47 & 2.15 \\
\hline 5 & 1.2 & 170 & 13.5 & 2.35 & 0.39 & 0.40 & 2.52 \\
\hline \multicolumn{8}{|c|}{$\mathrm{S} / \mathrm{C}$ M $400 \mathrm{D} 20$ cement consumption $370 \mathrm{~kg} / \mathrm{m}^{3}$} \\
\hline 1 & 0 & 60 & 87 & 2.29 & 2.4 & 2.49 & 0.40 \\
\hline 2 & 0.3 & 100 & 37 & 2.32 & 1.05 & 1.07 & 0.92 \\
\hline 3 & 0.6 & 130 & 15.5 & 2.33 & 0.45 & 0.45 & 2.19 \\
\hline 4 & 1 & 150 & 14 & 2.35 & 0.4 & 0.41 & 2.3 \\
\hline 5 & 1.2 & 170 & 12 & 2.36 & 0.35 & 0.35 & 2.82 \\
\hline
\end{tabular}

\section{Conclusions}

1. Analysis of the results obtained showed that with an increase in the consumption of cement and the content of the additive, the viscosity of the concrete mixture naturally decreases, especially significantly in 5-6 and 5-7 times at a dosage of KJ-3 1.0-1.2\%, respectively for PC M400 D0 and D20 (Fig. 2- 3.) a slightly lower value of the viscosity of the concrete mixture on the PC M 400 D20 is explained by additional plasticization due to the mineral additive (ash).

2. Comparison of the viscosity values obtained experimentally and calculated by the Einstein formula showed their practical comparability.

3. Consequently, Einstein's equation for calculating the viscosity of a concrete mixture can be used in practice since the error, in the overwhelming majority, is less than $4 \%$.

4. Thus, to obtain an effective concrete mixture with a low viscosity value, it is sufficient to use $1 \% \mathrm{KJ}-3$. A decrease in the viscosity of a concrete mixture should contribute to a significant increase in the duration of maintaining its fluidity, which has received experimental confirmation.

\section{References}

1. Technological instruction for the production of concrete and mortar mixtures at the BSU SB-75 at the MO-67 concrete and reinforced concrete construction site. TI 1384801-04-2006, (2006)

2. Kim K.N., Yazonkin V.I., Babaev V.A. Rheological properties of a concrete mixture with the addition of superplasticizers, M., In the book: Betones with effective superplasticizers, p.54, NIIZhB, (1989) 
3. Kim K.N. Methods for studying the rheological properties of concrete mixture, M., NIIZhB, vol. 29, pp. 2-16, (1987)

4. Gorchakov GL., Alimov LA. Voronin V.V., Uruev V.M. Instrument and method for establishing the rheological characteristics of concrete mixtures - Riga, Book. Rheology of concrete mixes and its technological problems.p. 252, (1989)

5. Volarovich M.P. Study of the rheological properties of dispersed systems. M., Colloid journal, 16, № 3, p. 20-23, (1984)

6. Gorchakov G.L., Alimov L.A. Voronin V.V., Uruev V.M. Instrument and method for establishing the rheological characteristics of concrete mixtures - Riga, Book. : Rheology of concrete mixes and its technological problems. p.252, (1979)

7. Bazhenov Yu.M. High-strength concrete with chemical additives, concrete and reinforced concrete, № 8, p. 29-31, (1977)

8. Kuntsevich O.V., Popova O.S. The use of water-soluble resins as additives to concrete, Concrete and reinforced concrete, № 7, p. 12-13, (1987)

9. Batrakov V.G., Issers F.A., Serykh R.L., Furmanov E.I. Properties of fine-grained mixtures and concretes with the addition of superplasticizers, concrete and reinforced concrete, № 10, p. 22-24, (1982)

10. Shaumarov S.S., Adilhodzhayev A.I., Kondrazhenko V.I. Experimental research of structural organization of heat-insulating structural building materials for energy efficient buildings. XXII International Scientific Conference on Advanced In Civil Engineering «Construction the formation of living environment», 2019. p. 1-7

11. The use of superplasticizers in concrete. Survey information, VNIIMS Gosstroy USSR, p. 58, (1982)

12. Ramachandran V. Additives to concrete: A reference guide, p.575, (1988)

13. Mirzaev B.K. Structure and properties of expanded clay concrete with complex polymer-mineral additives based on local raw materials, p. 16, Tashkent, TASI, (2020)

14. Batrakov V.G., Sobolev K.G., Kaprielov S.S., Silina E.S., Zhigulev N.F. Highstrength low-cement concretes, Chemical additives and their application in the technology of precast concrete production. Centre. Grew up. House of Knowledge, pp. 83-87, (1992)

15. Bazhenov Yu.M., Babaev Sh.T., Gruz A.I. and others. High-strength concrete based on superplasticizers, Building materials, № 9, pp. 21-24, (1988)

16. Akhverdov I.P. and other Properties of concrete with M-1 additive / Technology of concrete and composite materials, p. 50, Minsk, (1983)

17. A.A. Babin Concrete with a semi-functional superplasticizer based on light pyrolysis resin, p. 137. Belgorod, (2009)

18. Turgunbaev U.J., Umirova M. On the technology of obtaining reinforced concrete sleepers by heating concrete at low temperatures, Vestnik TashIIT, p. 109-115. (2020)

19. Batrakov V.G. Modified concrete. Theory and practice, M .: Higher school, p.768, (1998)

20. Bibik E.E. Rheology of dispersed systems, Publishing house of Leningrad University, p.172, (1981) 